\title{
Study on the Limitation of Intellectual Property Rights
}

\author{
Dongmei Huang
}

Weinan Normal University, Weinan, Shaanxi, 714000

\begin{abstract}
Keywords: Intellectual Property; Rights Limits; Internal Limits; External Limits
\end{abstract}
\begin{abstract}
The limitation of rights of intellectual property is divided into two systems: internal restriction and external restriction. Its main objective is to realize the legislative purpose and value goal of intellectual property. The internal limitation of intellectual property is narrow intellectual property restriction, which refers to the limitation of intellectual property law itself, such as the scope of protection, the term of protection and the limitation of intellectual property rights. Broad intellectual property restrictions, in addition to internal restrictions, but also in line with civil law norms, such as the prohibition of abuse of rights and other external restrictions. In recent years, restrictions on intellectual property rights are greatly influenced by science and technology. Therefore, under the influence of new technologies, it is necessary to give full play to the rights of intellectual property rights.
\end{abstract}

\section{Introduction}

In the 21st century, the knowledge economy has also entered a new era. Intellectual property rights affect the economic development. The intellectual property right restrictions have also become the focus of all walks of life in the society. In the era of knowledge economy, the limitation of the rights of intellectual property plays a crucial role in realizing the legislative aims and value goals of intellectual property law and in giving full play to the function and function of the intellectual property system in the new technological conditions. Based on the analysis of the current system and the legislative ideas on the future development trend, according to the balance of interests of intellectual property law and the relevant principles of law and economics, the paper analyzes the theoretical basis of rights restriction of intellectual property rights in detail and deeply studies the existing system , Discussing the new trend of restricting the development of the right of intellectual property and building a complete theoretical system of the restriction of the right of intellectual property so as to provide reference for the legislative practice of the restriction of the right of intellectual property in our country in the future.

\section{The theoretical basis for the limitation of intellectual property rights}

German jurist Jerin put forward the basis of rights is interests, rights is the law to recognize and safeguard the interests. The purpose of the law is to balance the interests of individuals and society, realize the combination of personal interests and social interests, and establish a personal and social partnership. Therefore, the existence of rights is the result of multiple interests and the need to balance each other. The limitation of the right of intellectual property is to find the balance point of conflicts of interest in the protection of intellectual property and to coordinate the multi-stakeholder interests is the key issue facing the limitation of current intellectual property rights. The limitation of the right of intellectual property is the result of the game of multi-stakeholder groups, and has never ceased in the course of hundreds of years of development. Social jurisprudence emphasizes the actual effect and purpose of society and proposes that the formulation of law should examine the social field in depth and make it become an effective means to meet the needs of society.

Economic analysis jurisprudence, as the name suggests, economic analysis of the method of law. The establishment of the system needs to be comprehensively explored through multi-angle and multidisciplinary studies. The theories and methods of economics can also provide new enlightenment for the study of the limitation of rights of intellectual property and how to effectively 
allocate resources to achieve the maximum benefit is the major part of economics content. The measure of efficiency in law and economics is the "Pareto Optimal" principle, that is, benefits must be optimized to the benefit of the country, society and individuals without compromising the interests of either party. The principle of law and economics is that the right of intellectual property restricts the basis of economic rationality, and it is also the theoretical basis of the reform that restricts property rights only.

\section{The legal system of intellectual property restrictions}

Restrictions on the rights of intellectual property mean that from the overall interests of the state, society and individuals, the content of intellectual property rights should be rationally bound. This kind of restraint is the price paid for the right of intellectual property and also the fairness and justice of the distribution of rights of intellectual property. The limitation of rights of intellectual property is the basic mechanism to realize the balance of interests of intellectual property, which guarantees the reasonable sharing of knowledge products and the balance of the exclusive rights of the intellectual property and the public interest, which promotes the prosperity and development of the culture to a certain extent. Intellectual property law is based on the dynamic utilization of knowledge wealth and confirms the dominance and ownership of creators of knowledge products. The intellectual property right restrictions are divided into internal and external restrictions in two ways, the two systems work together to form a complete system of intellectual property rights restrictions.

The internal limits of intellectual property are divided into three categories, namely, restrictions on the use of knowledge products, restrictions on the flow of knowledge-based products, and restrictions on public-owned materials. Depending on whether the use of intellectual achievements requires authorization, the need to pay fees is a limitation on the use of intellectual property. In the case of fair use, there is no need to obtain the owner's permission, and no need to pay them. Intellectual property is a special kind of goods that is related to the personal and social interests of the intellectual property people and has a strong public interest. Therefore, under certain conditions, the law allows the non-owners to carry out the rights without permission Reasonable use. Knowledge product is tangible, so it also has a tangible carrier. It will realize its inherent value in the process of circulation. It will lead to the monopoly conflict between the free flow of goods and intellectual property in the process of circulation, which requires the restriction of circulation of knowledge products to balance the interests of intellectual property owners and platforms, protect the legitimate rights and interests of intellectual property rights, promote the free flow of goods and safeguard the public's freedom of use. The so-called public rights material rights restrictions, that is, a clear division of the scope of public material, to protect social and public interests, and promote social science, culture and art development. Publicly-owned material is different from personal achievement. The use of public-owned material does not affect the interests of property owners protected by law and is therefore considered to be reasonable in business operations. Such as computer trademarks, the general computer body has the "Intel inside" this standard, which does not cause confusion with Intel, Intel does not harm the interests of the company, but also to enable the public to fully understand the relationship between products and services, protection The public should have the right to use resources reasonably and balance the interests of intellectual property owners and the general public.

External restrictions on intellectual property, that is, based on the basic principles of civil law and competition law to limit intellectual property rights. Article 4 of the "General Principles of Civil Law" in our country shall follow the principle of honesty and credibility in civil activities and Article 7, and prohibit the restriction on the exercise of intellectual property rights by the principle of abuse of right. Intellectual property is a category of civil rights. Its essence is private rights and honesty and credit are the basic principles in the field of private law. Therefore, the exercise of intellectual property rights should be limited by the principle of good faith. Intellectual property owners must also maintain the integrity of the gesture of ownership, not to deceive others and the public interest. The purpose of prohibiting abusive use of rights is to limit civil rights, protect the 
public interest, and ensure the balance between personal and public interests. Intellectual property is a kind of legal monopoly, so it is necessary to make reasonable restrictions on the obligee and prevent abuse by right holders. This is an effective supplement to the loopholes in law. Competition laws have clear limitations on IPR abuse of intellectual property rights and monopolistic behavior of IPR, encourage technological innovation at the expense of restraining and restricting competition, and enhance the creative power of IPR.

\section{Intellectual property rights limit the direction of development}

The balance of interests pursued by intellectual property law is a dynamic allocation process. Therefore, the intellectual property law needs to balance the interests of all parties. Interests are objective. When choosing the interests of the law, the law should comprehensively consider the current social environment and historical conditions. Comprehensive social and cultural, political and economic factors, so the limiting factors of intellectual property mainly scientific and technological level and political position.

In recent years, with the rapid development of digital information, the "sharing" of knowledge products has also become cheaper. The continuous expansion of public rights has caused a strong squeeze on the exclusive space of intellectual property and has infringed upon the interests of intellectual property owners Serious threat. The proliferation of social public interests, the restrictions on intellectual property appropriate anti-restrictions, give full play to the role of intellectual property rights restrictions. The antinomic limitation of intellectual property right restriction should start with the protection of the private right of intellectual property and restrict a system of the right itself, which is a new development direction of the current intellectual property right restriction system. International restrictions on intellectual property rights, including anti-restrictions include limiting the scope of the rational use, such as patent rights, the protection of new varieties of plants, etc .; followed by narrowing the scope of the rational use of use and expand the scope of statutory licensing. For example, public borrowing rights in countries such as Europe and the library are required to rent out and use the books, and the authors need to pay the author fees.

\section{The legislation of the limitation of intellectual property right in our country is perfect}

TRIPS (Agreement on Trade-Related Aspects of Intellectual Property Rights) referred to as intellectual property agreement. Article 8, paragraph 1, of the agreement clearly stipulates that members may take the necessary steps in the development or amendment of their domestic laws and ordinances to protect the public's health and development so as to increase their areas of vital importance to socio-economic and technological development in the public welfare, as long as the measures consistent with the provisions of this agreement. TRIPS gives members reasonable limits to intellectual property for the public interest and, in the light of actual conditions, balances the interests of all fields. Therefore, the balance between the private interest and the public interest in intellectual property is greatly influenced by the history and the external environment. Under certain historical circumstances, different countries choose different balance points according to their own national conditions. For example, developed countries use intellectual property rights restrictions, does not apply with developing countries. Even in the case of conflict between the protection of property rights and the public interest, even developed countries can weaken the private interests of intellectual property and safeguard the public interest. For example, after 9/11, anthrax appeared in the United States. They canceled the patent of Bayer's antibiotics in the United States, purchased ordinary replicas, and forced Bayer to sell 100 million pills to the United States at a low price. As far as China's current situation is concerned, our country is not suitable for a high degree of protection of intellectual property rights. Under the pressure of strong protection of intellectual property rights in developed countries, TRIPS flexibly uses its rights and limits to reduce the costs of using foreign knowledge products and guarantee China's scientific research and innovation activities carried out smoothly. 
One of the systems that restrict intellectual property is the compulsory licensing system. Both the developed countries and the developing countries will pay great attention to the design of this system and its future direction. However, the attitude between the two is also inconsistent. The purpose of the developed countries is to improve the conditions for the use of the system, while the developing countries on the other hand, on the other hand. Article 31 of the IPR Agreement sets forth the system of compulsory licensing and at the same time complements the restrictions on the compulsory license system, balancing the interests of developing and developed countries. If we can enhance the effectiveness of the compulsory licensing system without any conflict with the developed countries, we must find a reasonable justification based on the law. Such as national security, the public interest, education, scientific research and other non-profit activities, and made a loss of interest compensation.

In recent years, with the rapid spread of information technology, abuse of intellectual property has become a serious problem. Multinational corporations have high-tech products and obtain the corresponding market dominance with the intention of restricting competition and monopolizing the market. Chinese enterprises want to safeguard their own rights and interests, and create a fair and free market competition atmosphere, we need to be protected by the antitrust law. The area of application of antitrust law is the field of intellectual property. In the process of formulating the antitrust law, we must also ensure that the abuse of intellectual property rights occurs. According to our national conditions, we should learn from the foreign competition law provisions and reasonably adjust our antitrust law.

\section{Conclusion}

The limitation of the right of intellectual property is an important research topic in the law of intellectual property. Based on the restriction of the right of intellectual property, this article makes an in-depth analysis of the legal system and the future development of the limitation of intellectual property rights. Provide all-sided theoretical support, combined with China's national conditions, to improve China's intellectual property rights to limit the legislative system to provide appropriate reference.

\section{References}

[1] Zhang Derin Competition and Anti-Unfair Competition - Anti-Unfair Competition Theory Practice and Foreign Legal Standards [J] People's Daily Press, 1994

[2] Douglas C. North, Li Yi Ping translation structure and change in economic history [M] Commercial Press 1999

[3] Wang Xianlin Intellectual Property and Antitrust Law [M] Law Press 2001

[4] Feng Xiaoqing intellectual property law philosophy [M] Chinese People's Public Security University Press 2003,1 